\title{
Matériá
}

ISSN 1517-7076

Revista Matéria, v. 11, n. 4, pp. 412 - 419, 2006

http://www.materia.coppe.ufrj.br/sarra/artigos/artigo10818

\section{Estudo da Inserção de Grupos Iônicos em Polímeros Termorresistentes através de Planejamento de Experimentos}

\author{
Márcia G. de Azevedo ${ }^{1}$, Ana Lucia D. Skury ${ }^{2}$, Cristiano P. Borges ${ }^{1}$, M. Eugênia R. Sena ${ }^{3}$ \\ ${ }^{1}$ Lab de Processos de Separação com Membranas PAM/COPPE/UFRJ, CP: 68502. Ilha do Fundão, Rio de \\ Janeiro, RJ, 21941-972 \\ e-mail: mbastos@peq.coppe.ufrj.br, cristiano@peq.coppe.ufrj.br, \\ ${ }^{2}$ Lab de Mat.Superduros LAMAV/CCT/UENF, Av. Alberto Lamego, 2000, Campos dos Goytacazes, RJ, \\ 28013-600 \\ e-mail: 1ucia@uenf.br, \\ ${ }^{3}$ Lab de Membranas IQ/DTPB/ UERJ, Rua São Francisco Xavier, 524, Maracanã, Rio de Janeiro, RJ, \\ 20550-900 \\ e-mail: eugenias@uerj.br
}

\section{RESUMO}

O objetivo deste trabalho foi investigar a influência da inserção dos grupos sulfônicos na poli(éterimida) comercial, PEI, sobre as propriedades físico-químicas do polímero modificado, principalmente, através da capacidade de permear seletivamente prótons ou cátions, quantificada através da capacidade de troca iônica $(\mathrm{CTI})$, sorção em água $\left(\% \mathrm{H}_{2} \mathrm{O}\right)$ e viscosidade intrínsica $([\eta])$. Estes dados experimentais e o modelo estatístico obtido através das variáveis de controle (condições de síntese) e variáveis de respostas

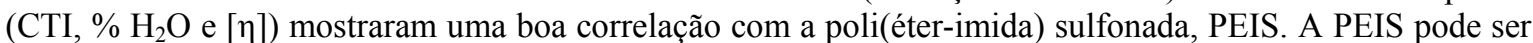
obtida, sem perda na estabilidade térmica, condição necessária para o preparo de filmes flexíveis com promissora aplicação em pilha combustível e em outros processos de separação que envolvam o transporte de íons. A PEIS foi obtida através da solubilização do polímero precursor em N-metil-2-pirrolidona (NMP) e adição do sulfato de acetila, como agente sulfonante. Os valores da CTI obtidos por titulação dos grupos sulfônicos presentes mostraram que todos os polímeros foram eficientemente sulfonados. Entretanto, uma variação no grau da capacidade de troca iônica foi observada em função da temperatura reacional, que também contribuiu na redução da viscosidade intrínseca dos polímeros modificados. Estes resultados provavelmente são devidos à presença de reações secundárias que ocorrem durante a sulfonação dos polímeros. A análise termogravimétrica do polímero original mostrou que a degradação da cadeia inicia em temperatura acima de $550^{\circ} \mathrm{C}$, com perda de massa em um único estágio, enquanto os polímeros sulfonados apresentam adicional estágio de perda de massa, na região entre $200-250^{\circ} \mathrm{C}$, e pode ser atribuída a dessulfonação. Contudo, a temperatura de degradação do polímero modificado, PEIS, ainda é mais elevada do que a Nafion ${ }^{\mathrm{TM}}$, o que torna este polímero útil para aplicações em transporte de íons.

Palavras chaves: Sulfonação; polímeros termorresistentes; membranas de troca catiônica.

\section{Investigation of Ionic Groups Insertion in Thermoresistant Polymer by Experimental Planning}

\section{ABSTRACT}

The objective of this work was to investigate the influence of the sulfonic groups during insertion at commercial poly(ether imide), PEI, on the physicochemical properties of modified polymer, principally through the permeselectivity of protons or cations, quantified by ion-exchange capacity (IEC), water sorption $\left(\% \mathrm{H}_{2} \mathrm{O}\right)$ and intrinsic viscosity $([\eta])$. These experimental data and model approach obtained from control

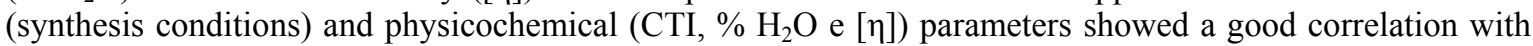
the sulfonated poly(ether imide), SPEI. The SPEI can be obtained without loss of mechanical and thermal stability, the main condiction to prepare flexible films with a promise at fuel cell application and other separation processes involving ion transport. The Polyetherimide (PEI) is a thermostable engineering polymer used as potential substitutes for commercial perfluorinated ionomers, Nafion ${ }^{\mathrm{TM}}$. The SPEI was obtained by dissolving the precursor polymer at the NMP and addition of acetyl sulfate, as sulfonated agents. The IEC values obtained by titration of sulfonic acid groups showed that all the polymers were effectively 
sulfonated. However, the variation at IEC degrees was observed as a function of temperature reaction, which also decreases the intrinsic viscosity of modified polymers. These results probably are due to the presence of secondary reactions that occur during the polymer sulfonation. The thermogravimetric analysis of original polymer showed a degradation temperature of backbone above $500^{\circ} \mathrm{C}$ with only one weight loss, while the sulfonated poly(ether imide), PEIS, exhibit an additional weight loss in the range $200-250^{\circ} \mathrm{C}$, and can be attributed to desulfonation. Nevertheless, in comparison with commercial polymers the degradation temperature of PEIS still is high, which turns this polymer useful for applications involving ion transport.

Keywords: Sulfonation; thermoresistant polymer; cation-exchange membranes.

\section{INTRODUÇÃO}

As membranas de troca catiônica são aplicadas em diversos processos que envolvem potencial elétrico tais como: eletrodiálise, diálise, osmose inversa e eletrólise $[\underline{1}, \underline{2}]$. Atualmente, com a procura de uma forma alternativa de produção de energia menos prejudicial ao meio ambiente, as membranas de troca catiônica têm sido utilizadas em células a combustível, tornando-as importantes no cenário de energias alternativas, porém uma das limitações da membrana atualmente empregada em células a combustível é suportar as temperaturas elevadas das células. E para se obter membranas economicamente viáveis, e com característica térmica superior a da Nafion ${ }^{\mathrm{TM}}$, novos eletrólitos condutores de prótons que alcancem alto desempenho e que tenham baixo custo são estudados $[\underline{3}, \underline{4}]$.

$\mathrm{O}$ desenvolvimento de um material polimérico para a obtenção de membranas que resistam às condições operacionais do processo, visa estabilidade química e eletroquímica, além de boa resistência térmica e mecânica. Uma das formas de se obter membranas poliméricas trocadoras de prótons utilizadas nas células a combustível (PEMFCs) tem sido a modificação química de polímeros termorresistentes, como poli(sulfonas), poli(éter sulfonas), poli(éter cetonas), poli(imidas), poli(benzimidazol), poli(oxadiazóis) e outros, através da introdução de um grupo iônico (sulfônico) na unidade estrutural polimérica [్-ㅁ].

A literatura registra três métodos principais para sulfonação de polímeros: sulfonação da cadeia principal, enxerto por radiação com subseqüente sulfonação, e reação de polimerização com monômeros sulfonados. A Figura 1 apresenta a estrutura química da PEI.

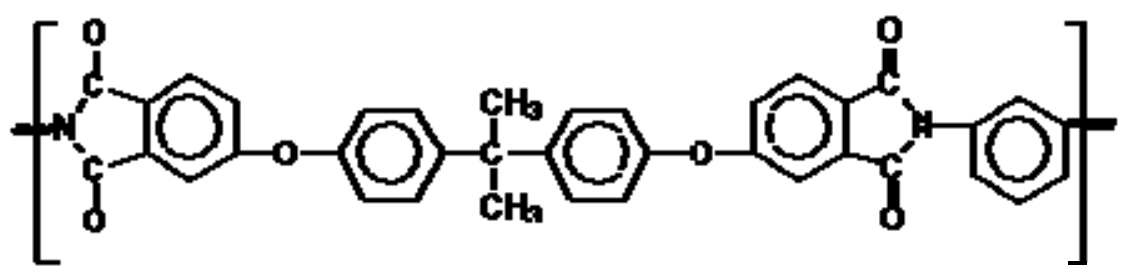

Figura 1: Estrutura química da Poli(éter imida), (PEI).

Uma característica importante desse polímero é a rigidez da cadeia polimérica, que confere uma baixa densidade de empacotamento molecular []].

A modificação química da PEI, por sulfonação da cadeia principal, foi conduzida em condições moderadas para minimizar a degradação polimérica. A otimização desta reação e das propriedades da PEI modificada, PEIS, foi realizada através de um planejamento experimental, utilizando um plano fatorial a dois níveis com replicas no ponto central.

\section{MATERIAIS E MÉTODOS}

\subsection{Materiais}

A poli(éter imida), PEI (Ultem 1000), foi adquirida da GE. O N-metil-2- pirrolidona, NMP, (99\%), o álcool isopropílico (99,5\%), o ácido sulfúrico (99\%) e o anidrido acético (99\%) foram adquiridos da Vetec. Os reagentes foram utilizados conforme recebidos. 


\subsection{Condições de Síntese}

A modificação do polímero termorresistente selecionado foi a sulfonação. A síntese da modificação ocorreu na faixa de temperatura entre $40-80{ }^{\circ} \mathrm{C}$, com duração de 2-6 h, e com quantidade dos reagentes determinada em função de $0,8-1,2$ moles do polímero, utilizando o sulfato de acetila obtido da mistura précondicionada, em banho resfriado a $0{ }^{\circ} \mathrm{C}$, do ácido sulfúrico e anidrido acético.

A reação foi realizada em um balão de 3 bocas, com agitação mecânica, condensador e entrada de nitrogênio para manter a atmosfera da reação livre de oxigênio e umidade. Inicialmente o polímero, PEI, é solubilizado no solvente NMP e depois se adiciona o sulfato de acetila, já condicionado a temperatura ambiente. A mistura fica sob agitação na temperatura reacional desejada até formar uma solução homogênea. Ao término da reação o polímero é precipitado em álcool isopropílico, filtrado a vácuo e seco em estufa a $60{ }^{\circ} \mathrm{C}$.

\subsection{Planejamento Fatorial Utilizado para o Estudo da PEI Sulfonada}

Com o objetivo de investigar as contribuições das variáveis de síntese dos polímeros sulfonados, temperatura, tempo de reação e concentração polimérica, foi elaborado um planejamento fatorial $2^{3}$ [10], com réplicas no ponto central. As variáveis independentes e os níveis dos fatores se encontram na Tabela 1.

Tabela 1: Variáveis independentes e os níveis dos fatores do planejamento

\begin{tabular}{ccc}
\hline & \multicolumn{2}{c}{ Níveis } \\
Variáveis independentes & Inferior (-1) & Superior $(+\mathbf{1})$ \\
\hline Temperatura $\left(\mathrm{T},{ }^{\circ} \mathrm{C}\right)$ & 40 & 80 \\
Tempo $(\mathrm{t}, \mathrm{h})$ & 2 & 6 \\
Concentração do Polímero $(\mathrm{P}, \mathrm{mol})$ & 0,8 & 1,2 \\
\hline
\end{tabular}

Como resposta ao sistema estudado foi utilizada a capacidade de troca iônica dos polímeros obtidos segundo as condições listadas na Tabela 2.

\subsection{Caracterização}

As propriedades térmicas dos polímeros sulfonados foram obtidas através de análise termogravimétrica (modelo TGA 7 da Parkin Elmer, calibrado com padrões de transição magnética. A análise foi realizada sob atmosfera de nitrogênio superseco na vazão de $54 \mathrm{~mL} / \mathrm{min}$. Foram realizadas duas corridas. Na primeira, a taxa de aquecimento foi de $20{ }^{\circ} \mathrm{C} / \mathrm{min}$ em um intervalo de $50{ }^{\circ} \mathrm{C}$ a $150{ }^{\circ} \mathrm{C}$, para a remoção da umidade. A partir desse procedimento a massa da amostra foi determinada. Na segunda corrida, a taxa de aquecimento foi de $10{ }^{\circ} \mathrm{C} / \mathrm{min}$ em um intervalo de $50{ }^{\circ} \mathrm{C}$ a $700{ }^{\circ} \mathrm{C}$, determinando-se a perda de massa referente a degradação dos grupos sulfônicos $\left(200-250^{\circ} \mathrm{C}\right)$ e da cadeia principal (acima de $\left.450^{\circ} \mathrm{C}\right)$.

Para a determinação da viscosidade intrínseca foi utilizado um viscosímetro Ostwald $\mathrm{n}^{\circ} 300$, diâmetro interno de $1,27 \mathrm{~mm}$. As medidas foram realizadas a $26{ }^{0} \mathrm{C}$ utilizando três soluções em ácido sulfúrico, com concentrações de $0,125,0,250$ e $0,500 \mathrm{gdL}^{-1}$. Os resultados foram considerados quando três medidas do tempo de escoamento, no mínimo, foram reproduzidas. A viscosidade intrínseca foi determinada conforme metodologia descrita por GOMES [11].

A Capacidade de Troca Iônica (CTI) foi avaliada convertendo os polímeros sulfonados (ca. 5g) na forma ácida $\left(\mathrm{H}^{+}\right)$com $\mathrm{HNO}_{3}(1 \mathrm{M})$, cujo excesso foi removido por sucessivas lavagens com água destilada. Uma parte da amostra (ca. $1 \mathrm{~g}$ ) foi colocada em solução de $\mathrm{NaOH}\left(0,1\right.$ molL $\left.^{-1}\right)$, deixando a amostra em repouso por $24 \mathrm{~h}$. Alíquotas do líquido sobrenadante foram tituladas com solução padronizada de $\mathrm{HCl}(0,1 \mathrm{~N})$. A capacidade de troca catiônica é calculada pela Equação 1, abaixo [12]:

$$
C T I=\frac{\left(200 \mathrm{~mL} \times N_{\mathrm{NaOH}}\right)-4\left(m L_{\mathrm{HCl}} \times N_{\mathrm{HCl}}\right)}{\text { Peso da Amostra } \times \text { Sólidos } \% / 100}=M e q \cdot g_{H^{+}}^{-1}
$$




\section{RESULTADOS E DISCUSSÕES}

\subsection{Análise Termogravimétrica}

A análise termogravimétrica foi efetuada para avaliar a resistência térmica do polímero modificado e correlacionar o grau de sulfonação com a capacidade de troca iônica, determinada por titulação. $\mathrm{Na}$ Figura 2 apresentam-se os termogramas do polímero precursor PEI, dos polímeros sulfonados, PEI-S; assim como de uma membrana comercial sulfonada, Nafion ${ }^{\mathrm{TM}}$.

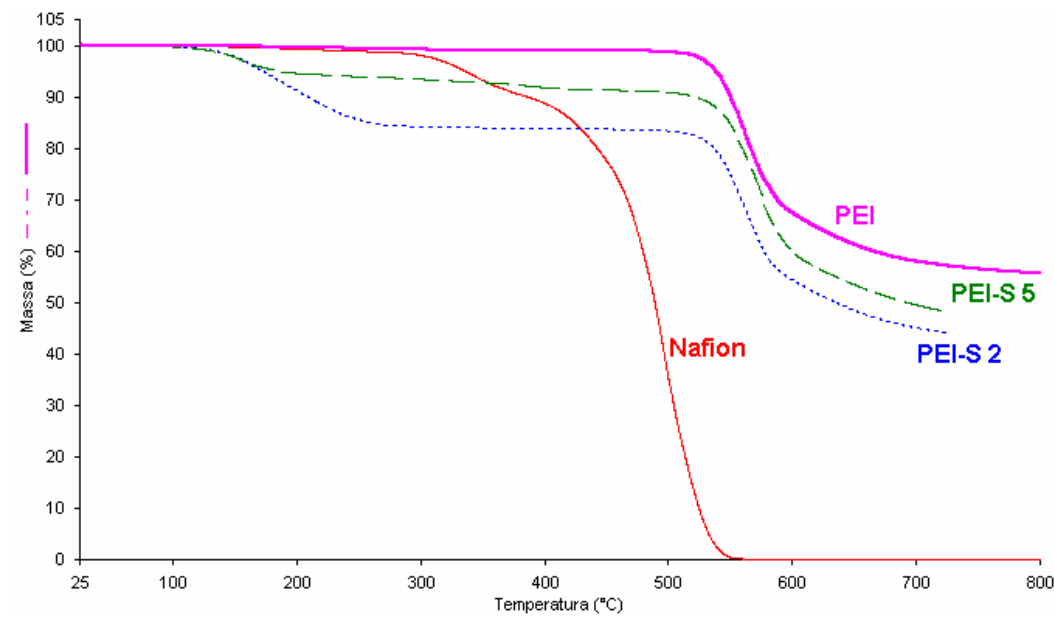

Figura 2: Termograma das amostras de PEI, PEIS e da membrana de Nafion ${ }^{\text {TM }}$. PEI-S2: polímero sulfonado na condição 2 da Tabela 2. PEI-S5: polímero sulfonado na condição 5 da Tabela 2.

Como observado nos termogramas da Figura 2, a PEI é estável termicamente, iniciando sua decomposição no intervalo de $500{ }^{\circ} \mathrm{C}$ a $550{ }^{\circ} \mathrm{C}$. No caso dos polímeros modificados, PEIS, observou-se uma etapa inicial de perda de massa, ocorrendo no intervalo de $150{ }^{\circ} \mathrm{C}$ a $250{ }^{\circ} \mathrm{C}$, que pode ser atribuída a dessulfonação parcial do polímero.

A etapa seguinte, entre $450{ }^{\circ} \mathrm{C}$ a $550^{\circ} \mathrm{C}$, pode ser atribuída à decomposição da cadeia polimérica. Resultados similares a estes foram obtidos nos estudos realizados por Lufrano [7], onde são comparada amostras de poli(sulfonas) sulfonadas e não sulfonadas. A membrana de Nafion ${ }^{\mathrm{TM}}$, que contém grupos $\mathrm{SO}_{3} \mathrm{H}$, também apresenta duas regiões de perda de massa, a primeira ocorrendo entre $280{ }^{\circ} \mathrm{C}$ a $300{ }^{\circ} \mathrm{C}$, superior a região dos polímeros sulfonados (PEIS) e a segunda, iniciando após $400{ }^{\circ} \mathrm{C}$. A comparação com os polímeros sulfonados mostra a maior estabilidade térmica da PEIS em relação à membrana de Nafion ${ }^{\mathrm{TM}}$. $\mathrm{O}$ termograma das amostras de PEI-S2 e PEI-S5 mostram que o grau de sulfonação da amostra S2 é maior do que a amostra S5, apresentando maior perda de massa na região de dessulfonação, a 150-250 ${ }^{\circ} \mathrm{C}$. Apesar de este resultado ser muito representativo, a capacidade de troca iônica destas amostras é aproximadamente igual. Uma análise mais detalhada da influência das condições de síntese sobre a CTI deverá ser investigada.

\subsection{Propriedades Físico-Químicas dos Polímeros}

Os valores obtidos para as propriedades físico-químicas, tais como viscosidade intrínseca [y], sorção de água e capacidade troca iônica (CTI) dos polímeros Nafion ${ }^{\mathrm{TM}}$, PEI e PEIS nas condições experimentais investigadas, são apresentados na Tabela 2 .

O comportamento da viscosidade intrínseca dos polímeros sulfonados foi idêntico, ou seja, após a introdução dos grupos substituintes, ocorreu uma redução na viscosidade intrínseca, indiciando uma correspondente redução na massa molar, comparado com o polímero precursor, PEI. Considerando os resultados da análise termogravimétrica, onde se observou uma pequena redução da termoestabilidade nos polímeros sulfonados, pode-se concluir que esta modificação leva a uma degradação parcial da estrutura principal do polímero original.

Os resultados dos testes de sorção de água e determinação da capacidade de troca iônica confirmam a presença dos grupos substituintes nas amostras de PEIS. Uma amostra da membrana de Nafion ${ }^{\mathrm{TM}}$ também foi utilizada nesses testes para efeito de comparação. 
Tabela 2: Valores das medidas de viscosidade intrínseca, capacidade de troca iônica e sorção de água.

\begin{tabular}{c|c|c|c|c|c|c}
\hline \multicolumn{3}{c|}{ Variáveis de Controle } & \multicolumn{3}{c}{ Variáveis Respostas } \\
\hline $\mathbf{N E}$ & $\mathbf{T}\left({ }^{\mathbf{0}} \mathbf{C}\right)$ & $\mathbf{t}(\mathbf{h})$ & {$[\mathbf{P}](\mathbf{m o l})$} & $\mathbf{C T I}$ & $\mathbf{H}_{\mathbf{2}} \mathbf{O}(\mathbf{\%})$ & {$[\mathbf{\eta}]$} \\
\hline 1 & 40 & 2 & 0,8 & 0,92 & 0,94 & 0,55 \\
\hline 2 & 40 & 2 & 1,2 & 1,36 & 0,64 & 0,35 \\
\hline 3 & 40 & 6 & 0,8 & 1,26 & 0,78 & 0,41 \\
\hline 4 & 40 & 6 & 1,2 & 0,90 & 3,35 & 0,40 \\
\hline 5 & 80 & 2 & 0,8 & 1,39 & 1,26 & 0,44 \\
\hline 6 & 80 & 2 & 1,2 & 0,87 & 1,29 & 0,45 \\
\hline 7 & 80 & 6 & 0,8 & 1,01 & 0,61 & 0,47 \\
\hline 8 & 80 & 6 & 1,2 & 1,10 & 1,61 & 0,41 \\
\hline 9 & 60 & 4 & 1,0 & 0,96 & 0,90 & 0,49 \\
\hline 10 & 60 & 4 & 1,0 & 0,85 & 1,28 & 0,48 \\
\hline 11 & 60 & 4 & 1,0 & 0,85 & 0,46 & 0,50 \\
\hline \multicolumn{3}{c|}{ PEI } & & - & 0,10 & 0,78 \\
\hline \multicolumn{3}{c|}{ Nafion ${ }^{\text {TM }}}$. & 1,85 & 15,0 & - \\
\hline
\end{tabular}

$\mathrm{NE}=\mathrm{n}^{\circ}$ de experimento, $[\mathrm{P}]=$ concentração do polímero

A natureza hidrofílica dos polímeros sulfonados aumenta com o grau de sulfonação, quantificada pela sorção de água das amostras, apresenta uma correlação linear com a capacidade de troca iônica (CTI). Isto mostra que os grupos sulfônicos foram incorporados na matriz polimérica.

Sendo a capacidade de troca iônica uma das principais propriedades requeridas em membranas sulfonadas, é interessante avaliar como as variáveis de sínteses influenciam sobre esta propriedade. Para este fim foi utilizado o software Statistica ${ }^{\circledR}$. A partir dos dados da Tabela 2 foi elaborado um modelo matemático. Após a análise estatística pertinente chegou-se a Equação 2.

$$
C T I=0,89-0,06 t p+0,18 t T p+0,22 T^{2}
$$

Este modelo apresentou um coeficiente de correlação de 0,954 e uma variância explicada de $91 \%$. Estes dados indicam que somente alguns efeitos de segunda e terceira ordens foram significativos, assim como a inclusão de um termo quadrático para a temperatura.

A correlação entre os valores preditos pelo modelo e os valores experimentais obtidos é mostrada na Figura 3. O grau de predição do modelo pode ser considerado satisfatório, uma vez que somente poucos pontos encontram-se fora do limite de confiança de $95 \%$.

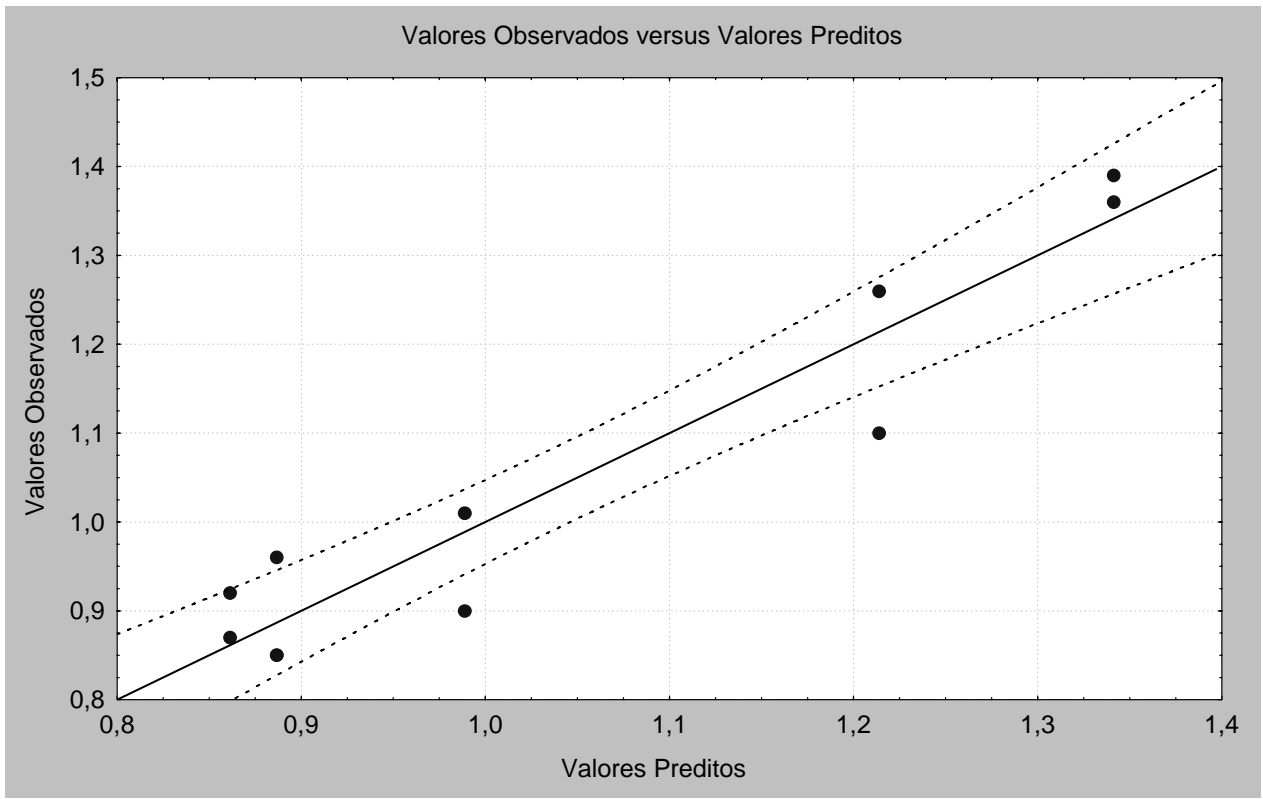

Figura 3: Valores preditos versus valores observados. 
Com base neste modelo é possível pesquisar o ponto dentro do domínio investigado no qual a CTI é máxima. Para este fim foram construídas as curvas de nível utilizando-se o software Surfer®.

Conforme pode ser notado na Equação 2, a maior CTI pode ser alcançada quando as variáveis são fixadas no nível superior. Assim sendo, foram construídas três curvas relativas a cada variável fixada no nível superior. Nas Figuras de 4 a 6 encontram-se representadas as curvas obtidas.

Comparando-se os dados da Tabela 2 com os gráficos das Figuras 4, 5 e 6 conclui-se que a CTI é mais sensível à variação da temperatura e da concentração do polímero do que com o tempo. Os maiores valores de CTI foram obtidos em duas condições distintas: temperatura baixa e concentração alta ou temperatura alta e concentração baixa. Nota-se também que, dependendo dos níveis de concentração e da temperatura, o aumento do tempo de processo está diminuindo os valores da CTI dos polímeros. Este fato é bem evidenciado comparando-se os ensaios 5 e 7 apresentados na Tabela 2 .
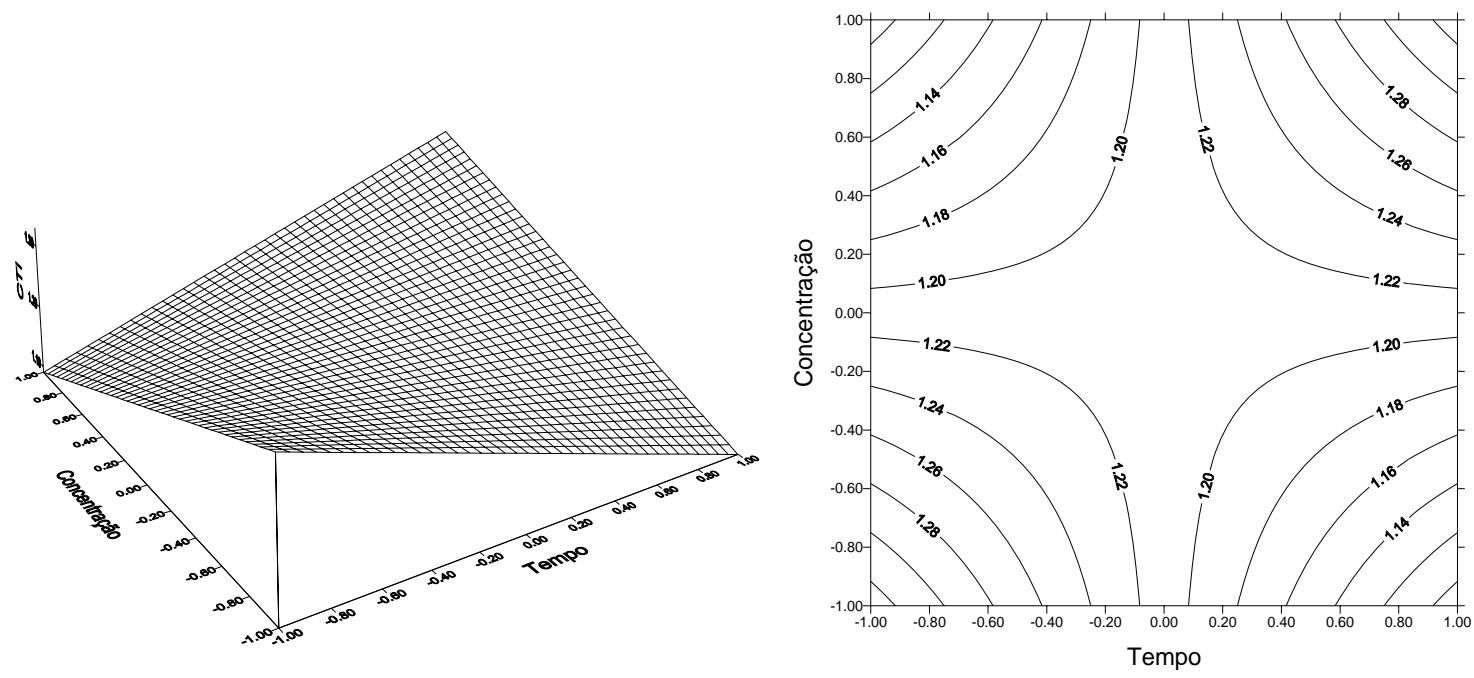

Figura 4: Superfície e curva de nível geradas a partir da Equação (2) para $T=+1$.
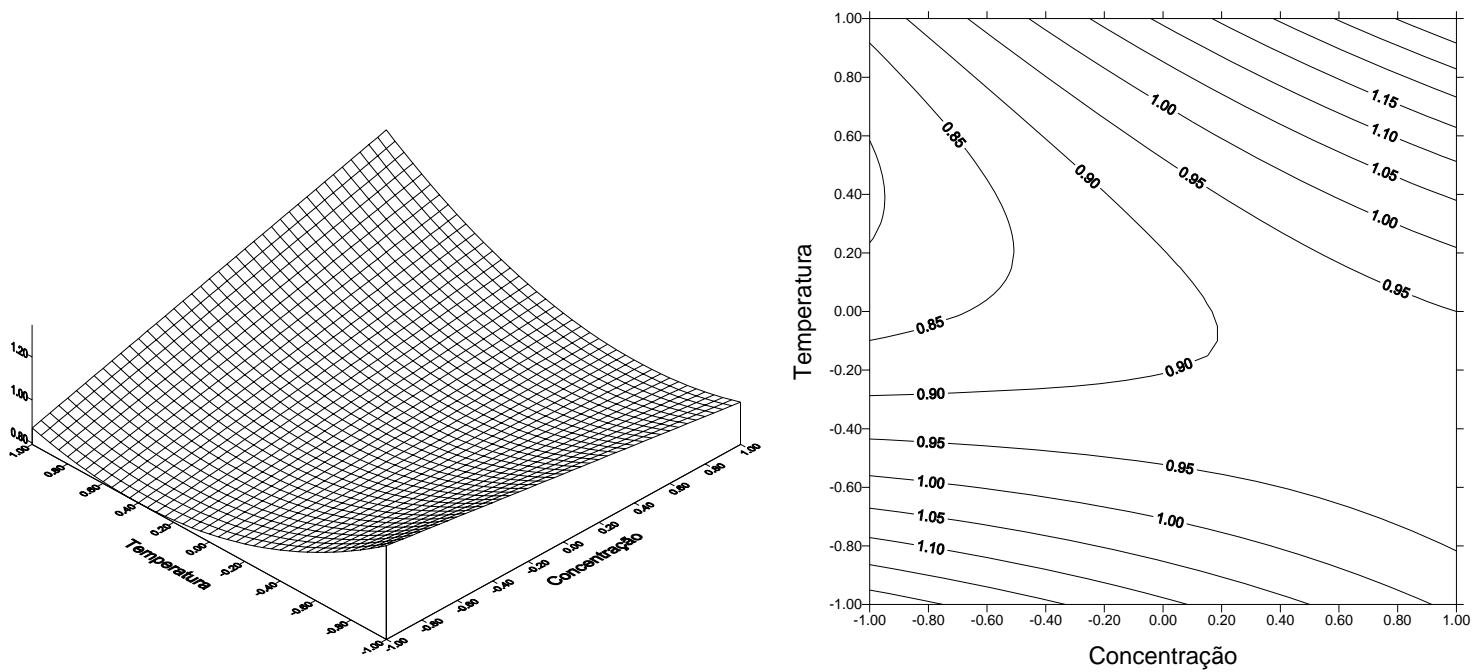

Figura 5: Superfície e curva de nível geradas a partir da Equação (2) para $t=+1$. 

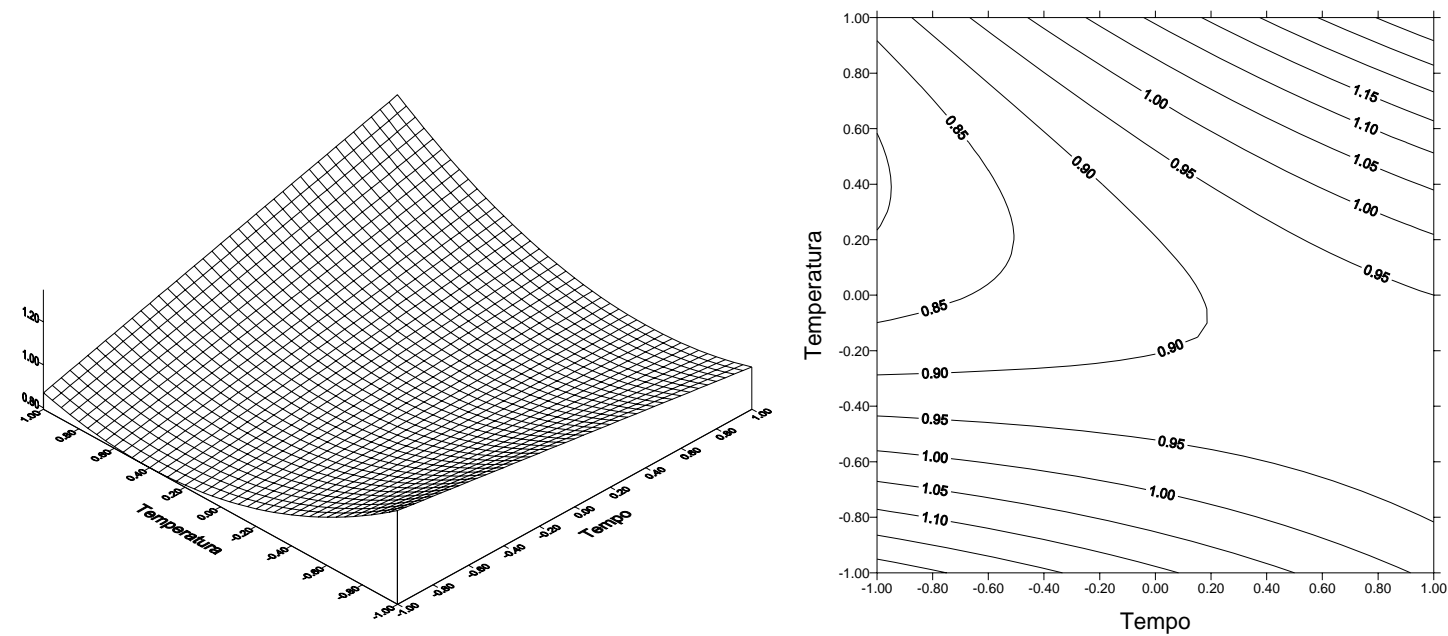

Figura 6: Superfície e curva de nível geradas a partir da Equação (2) para $\mathrm{P}=+1$.

Finalmente, a análise da Equação 2 e dos gráficos das Figuras de 4 a 6 mostra que para a otimização do processo o planejamento deve ser deslocado para regiões de maiores valores de concentração e temperatura. Entretanto, deve-se ter em mente que o aumento excessivo da temperatura poderá acarretar na degradação do polímero. Assim sendo, mais estudos nesta área se fazem necessários para avaliar a influência do teor de grupos sulfônicos nas propriedades de troca iônica da membrana.

\section{CONCLUSÕES}

As condições empregadas para as reações de sulfonação foram efetivas na introdução de grupos substituintes no polímero selecionado, PEI. Os polímeros sulfonados, com grupos substituintes pendentes na cadeia, levaram a perda de massa na região entre $150-250^{\circ} \mathrm{C}$, contribuindo em pequena redução da termoestabilidade, comparada com o polímero original. Entretanto, a PEI sulfonada apresenta estabilidade térmica superior a membrana comercial Nafion, o que possibilita maior tempo de vida útil para a membrana de troca iônica, em especial quando aplicada temperatura superior a ambiente.

\section{BIBLIOGRAFIA}

[1] SHAPOSHNIK, V.A., KESORE, K., "An Early History of Electrodialysis with Permselective Membranes", Journal of Membrane Science, v. 136, pp. 35 - 39, 1997.

[2] SATA, T., SATA, T., YANG, W., "Studiers on cation-exchange Membranes Having Permseletivity Between Cations in Electrodialysis", Journal of Membrane Science, v. 206, pp. 31 - 60, 2002.

[3] WENDT, H., GÖTZ, M., LINARD, M., “Tecnologia de Células a Combustível”, Química Nova, v. 23, n. 4,2000

[4] WOO, Y., OH, Y. SE, KANG, Y. S., JUNG, B., "Synthesis and Characterization of Sulfonated Polyimide Membranes for Direct Methanol Fuel Cell”, Journal of Membrane Science, v. 220, pp. 31-45, 2003.

[5] GLIPA, X., HADDAD, M.E., JONES, D.J., ROZIÈRE, J., "Synthesis and Characterization of Sulfonated Polybenzimidazole: A Highly Conducting Proton Exchange Polymer", Solid State Ionics, v. 97, pp. 323-331, 1997.

[6] HWANG, G.-J., OHYA, H., NAGAI, T., "Ion Exchange Membrane based on block Copolymers. Part III: Preparation of cation exchange Membrane", Journal of Membrane Science, v. 156, pp. 61-65, 1999.

[7] Lufrano, F., SQuAdrito, G., PATTI, A., PASSAlACQUA, E., "Sulfonated Polysofone as Promising Membranes for Polymer Electrolyte Fuel Cells", Journal of Applied Polymer Science, v.77, pp.1250-1257, 2000. 
[8] BASTOS, M.G.A., Polímeros Termorresistentes Modificados com a inserção de Grupos Iônicos para o Preparo de Membranas Seletivas de Íons, Tese de D.Sc., COPPE/UFRJ, RJ, Brasil, 2005.

[9] GIESELMAN, M.B., REYNOLDS, J.R., "Water - Soluble Polybenzimidazole - Based Polyelectrolytes", Macromolecules, v. 25, pp. 4832-4834, 1992.

[10] BARROS NETO, B., SCARMÍNIO, I.S., BRUNS, R.E., Planejamento e Otimização de Experimentos, Campinas, Editora da Unicamp, 1995.

[11] GOMES, D.F., PINTO, J.C., BORGES, C.P., "Evaluation of Parameter Uncertainties during the Determination of the intrinsic Viscosity of Polymer Solutions", Polymer, v. 41, pp. 5531-5534, 2000.

[12] KUNIN, R., Ion Exchange Resins, 2 ed. New York, Jonh Wiley e Sons, 1958. 